\title{
An Ethanolic Extract of Allium hookeri Root Alleviates Reflux Esophagitis and Modulates NF- $\kappa$ B Signaling
}

\author{
Li Nan, ${ }^{1}$ Hyeon Hwa Nam, ${ }^{1}$ Byung Kil Choo ${ }^{D},{ }^{1}$ Jin Cheon Park, ${ }^{1}$ Dae Geun Kim, \\ Jeong Ho Lee, ${ }^{2}$ and Kwang Hyun Moon ${ }^{2}$ \\ ${ }^{1}$ Department of Crop Science \& Biotechnology, Chonbuk National University, Jeonju 561-756, Republic of Korea \\ ${ }^{2}$ Sunchang Research Institute of Health and Longevity, Ingye-myeon Indeok-ro, Sunchang-gun, Jeollabuk-do 56015, Republic of Korea \\ Correspondence should be addressed to Byung Kil Choo; bkchoo@jbnu.ac.kr
}

Received 28 February 2018; Revised 26 August 2018; Accepted 30 September 2018; Published 8 October 2018

Academic Editor: Jae Youl Cho

Copyright (C) 2018 Li Nan et al. This is an open access article distributed under the Creative Commons Attribution License, which permits unrestricted use, distribution, and reproduction in any medium, provided the original work is properly cited.

Reflux esophagitis (RE) is a kind of gastroesophageal reflux disease, of which an esophageal inflammatory lesion is caused by the contents of the stomach and duodenum flowing back into the esophagus. Allium hookeri is a plant possessing both nutritional and medicinal properties. In our study, we investigated the inhibition effect of inflammation of A. hookeri root extract (AHE) on inflammatory RAW264.7 macrophage cells induced by lipopolysaccharide and rat models of RE. The results showed that AHE significantly reduced the production of nitric oxide (NO) and the protein expression levels of various mediators related to inflammation including inducible nitric oxide synthase (iNOS), cyclooxygenase-2 (COX-2), and inflammatory cytokines such as interleukin-1 beta (IL-1 $\beta$ ) and tumor necrosis factor-alpha (TNF- $\alpha$ ). Furthermore, AHE also inhibited the nuclear translocation of nuclear factor kappa B (NF- $\kappa \mathrm{B}$ ) by inhibiting the phosphorylation $\mathrm{I} \kappa \mathrm{B} \alpha$. In addition, AHE administration significantly ameliorated esophageal mucosal damage upon histological evaluation of RE in rats. AHE was also found to downregulate the expression levels of proteins such as COX-2, TNF- $\alpha$, and IL- $1 \beta$ in the rat esophagus. AHE markedly attenuated activation of NF- $\kappa$ B and phosphorylation of $\mathrm{I} \kappa \mathrm{B} \alpha$ at the same time. These results indicated that AHE suppressed LPS-induced inflammatory responses in RAW264.7 cells and may help reduce the development of esophagitis through the modulation of inflammation by regulating NF- $\kappa$ B activation.

\section{Introduction}

Gastroesophageal reflux disease (GERD) is a disorder with prevalence up to $20-40 \%$ in America and Europe [1]. The prevalence of GERD is also increasing in the Asian areas [2]. GERD is a condition in which stomach contents which frequently flow back into esophagus cause troublesome symptoms and/or complications [3]. The main features of GERD include heartburn and acid regurgitation [4].

Reflux esophagitis (RE) is a kind of gastroesophageal reflux disease, which is an esophageal inflammatory lesion caused by the contents of the stomach and duodenum flowing back into the esophagus, that is, esophageal erosion or esophageal ulcer [5]. The main cause of RE is the destruction of the reflux barrier (lower esophageal sphincter). The LES is a high-pressure area within $3-5 \mathrm{~cm}$ above the junction between the esophagus and the stomach. It plays a physiological role in preventing the flow of stomach contents into the esophagus
[6]. Symptoms such as erosion and stenosis in the lower esophagus are considered to be typical complications of RE [7].

Inflammation is a defensive reaction to biological threats. However, persistent or prolonged inflammation may lead to the development of extensive tissue damage or disease, including cancer. The use of plant-based medicinal compounds for the reduction of inflammation has become a popular topic in recent years. In one study, paeonol, the main component of Moutan Cortex, has been shown to exhibit anti-inflammatory effects by decreasing the level of proinflammatory mediators [8]. In addition, ethanol extracts of Sanguisorba officinalis L. have been observed to inhibit both the degradation of $\mathrm{I} \kappa \mathrm{B} \alpha$ and the nuclear translocation of NF- $\kappa$ B p65, confirming its anti-inflammatory capacity [9].

Lipopolysaccharide is a component of the cell wall of Gram-negative bacteria and is toxic to the host [10]. It is always used to induce inflammatory responses in various 
experimental models [11]. Macrophages stimulated by LPS produce many proinflammatory factors and inflammatory mediators such as NO, iNOS, COX-2, TNF- $\alpha$, and IL- $1 \beta$ that regulated by $\mathrm{NF}-\kappa \mathrm{B}[12,13]$. Under homeostatic conditions, $\mathrm{NF}-\kappa \mathrm{B}$ binds to its inhibitory protein $(\mathrm{I} \kappa \mathrm{B})$ in the cytoplasm, assuming an inactive state. Stimuli such as LPS, TNF- $\alpha$, and IFN- $\gamma$ can induce the phosphorylation of $\mathrm{I} \kappa \mathrm{B}$ and resulting activation of NF- $\kappa \mathrm{B}$. The activated NF- $\kappa \mathrm{B}$ is transferred to the nucleus and binds to a specific DNA target site to regulate transcription of the target gene [14].

Allium hookeri (also known as Hooker chives or Kuan ye jiu) is a perennial herbaceous evergreen plant, distributed in Yunnan, Sichuan, and Southeastern China, as well as in Sri Lanka, Bhutan, and India $[15,16]$. The nutritional and medicinal properties of $A$. hookeri have been described previously. As a supplementary food, it contains various nutrients including sugars, phenol, phytosterols, vitamin C, fiber, and protein $[17,18]$. Some studies reported that these nutrients are present in higher quantities in $A$. hookeri than in Allium cepa $[12,19]$. Alliin, a garlic organosulfur compound, has been reported to inhibit LPS-induced inflammatory response $[20,21]$ and protect against LPS-induced acute lung injury [22]; the compound has been proven to be present in A. hookeri [23]. Meanwhile, the various medicinal effects of A. hookeri have been demonstrated to include anticoagulant [24], antidiabetic [25], anticholesterol [26], antibacterial [27], and antiobesity [28] activities. The root extract has also been shown to be beneficial for bone health and can lower blood glucose levels while increasing insulin sensitivity [29].

Although $A$. hookeri has been shown to have antiinflammatory effects, whether these effects extend to the inhibition of elements of RE is not well known. In this study, we investigated the therapeutic potential of $A$. hookeri root extract (AHE) in LPS-induced damage in the RAW264.7 macrophage cell line. Furthermore, we investigated the effect of this extract on rat models of RE to explore the possible underlying mechanisms of inhibition.

\section{Materials and Methods}

2.1. Materials. The protease inhibitor cocktail, PMSF, and EDTA were obtained from Sigma Aldrich (Seoul, Korea). LPS was purchased from Sigma Chemical Company. The Cell Viability, Proliferation \& Cytotoxicity Assay Kit was purchased from DoGenBio Co., Ltd. (Seoul, Korea). The bovine serum albumin standard, protein assay reagent, and PVDF were purchased from Bio-Rad Laboratories (Hercules, CA, USA). Griess reagent was obtained from Promega (Madison WI, USA). iNOS, COX- $2, \beta$-actin, $\mathrm{p}-\mathrm{I} \kappa \mathrm{B} \alpha, \mathrm{p}-\mathrm{NF}-\kappa \mathrm{B}$ p 65 , IL- $1 \beta$, and TNF- $\alpha$ antibodies and Luminol Reagent were purchased from Santa Cruz Biotechnology, Inc. (Santa Cruz, CA, USA).

2.2. Preparation of AHE. A. hookeri roots were purchased from Sunchon-myeon, Jeollabuk-do, Korea. After the roots are dried, they are ground into a powder. The powder was suspended in ten volumes of $75 \%$ ethanol and extracted for $2 \mathrm{~h}$ four times under a $50^{\circ} \mathrm{C}$ circulation distillation apparatus.
The ethanol extract was filtered, concentrated, lyophilized, and then stored at $-80^{\circ} \mathrm{C}$ until used.

2.3. Cell Culture. Macrophage of RAW264.7 cells was obtained from ATCC (Rockville, MD, USA). Cells were cultured in DMEM containing $10 \%$ heat-inactivated FBS (Welgene, Namcheon-ro, South Korea), 100 units/ml penicillin, and $100 \mu \mathrm{g} / \mathrm{ml}$ streptomycin. The cells are grown in a constant temperature incubator with a $\mathrm{CO}_{2}$ of $5 \%$ and a temperature of $37^{\circ} \mathrm{C}$.

2.4. Cell Viability and NO Assay. To determine cell viability, cells were distributed at a concentration of $5 \times 10^{5}$ cells $/ \mathrm{ml}$ on a 96-well cell culture plate. They were then treated with AHE $(125,250$, and $500 \mu \mathrm{g} / \mathrm{ml})$. After $1 \mathrm{~h}$, LPS $(1 \mu \mathrm{g} / \mathrm{ml})$ was added to the plate for an additional $24 \mathrm{~h}$. Viability of cells was determined by the Cell Viability, Proliferation \& Cytotoxicity Assay Kit. Determination of nitrite content in culture medium was using Griess reagent (Promega, Madison, WI, USA). The NO concentration was determined by measuring the absorption at $540 \mathrm{~nm}$ using a $\mathrm{NaNO}_{2}$ dilution set for a standard curve. Each treatment was carried out in triplicate.

2.5. Cell Protein Extraction. In order to extract the total protein of the cells, the cells were plated at a concentration of $1 \times 10^{6}$ cells $/ \mathrm{ml}$ in a $60 \times 15 \mathrm{~mm}$ cell culture dish and treated with AHE $(250$, and $500 \mu \mathrm{g} / \mathrm{ml})$ for $1 \mathrm{~h}$. LPS $(1 \mu \mathrm{g} / \mathrm{ml})$ was then added to the plate, and the cells were incubated for $1 \mathrm{~h}$ or 18 h. Cells were washed with PBS 3 times and then centrifuged at 4,000 rpm for $3 \mathrm{~min}$. The final pellet was lysed in 100 $\mu l$ RIPA lysis buffer with $150 \mathrm{mM} \mathrm{NaC1}, 5 \mathrm{mM}$ EDTA ( $\mathrm{pH}$ 8.0), 50 mM Tris ( $\mathrm{pH} 8.0$ ), 1 \% NP-40, $0.1 \%$ sodium dodecyl sulfate, $0.5 \%$ sodium deoxycholate, and protease inhibitor mixture solution on ice for $15 \mathrm{~min}$. The lysis mixture was then centrifuged at 13,000 rpm for $15 \mathrm{~min}$, and the supernatant was taken up in EP tube and stored at $-80^{\circ} \mathrm{C}$ until used.

2.6. Experimental Animals and Treatment. Sprague Dawley rats (7-week-old, body weight 200-220g) were housed in standard rat cages for experimentation, providing adequate food and water at all times, maintained in a 12-hour light/dark cycle, at a temperature of $21-25^{\circ} \mathrm{C}$ and a humidity of $35-$ $60 \%$. After one week of adaptation, the rats were randomly divided into 3 groups of 6 each which were normal group, RE control group, and drug treatment RE group. The rats were fasted $18 \mathrm{~h}$ before the operation but maintained water supply. Rats in the RE control group and the drug-treated RE group were intragastrically administered $1.5 \mathrm{~h}$ before the operation of inducing reflux esophagitis. The RE control group was physiological saline, and the drug treatment group was AHE at a concentration of $500 \mathrm{mg} / \mathrm{kg}$. Then the rats were subjected to respiratory anesthesia, and an incision of about $2 \mathrm{~cm}$ was cut in the middle part of the abdomen of the rat to expose the stomach, and then the stomach and pylorus junctions and the fundus were ligated to induce reflux, keeping the vagus nerve intact [30]. After $4.5 \mathrm{~h}$ of surgery, all rats were sacrificed. The esophagus was immediately removed and washed with saline, 
photographed (for the calculation of the degree of esophageal damage), and then the esophageal tissue was stored at $-80^{\circ} \mathrm{C}$ for later used.

2.7. Esophageal Injury Ratio. The esophagus of the rat was cut longitudinally, and the damaged part was exposed. After the photography, the image of the esophageal injury rate was calculated by ImageJ software [31]. The calculation method of the esophageal injury ratio is as follows: gross mucosal damage ratio $(\%)=$ [area of esophageal mucosal damage $\left(\mathrm{mm}^{2}\right) /$ total area of esophagus $\left.\left(\mathrm{mm}^{2}\right)\right] \times 100$.

2.8. Esophageal Histology Analysis. After the rat esophagus was removed, it was washed with physiological saline, then cut into small pieces of $2-3 \mathrm{~mm}$, and immersed in $10 \%$ of neutral buffered formalin. The esophageal specimens were rinsed, dehydrated, transparent, dipped in wax, embedded, sectioned $(5 \mu \mathrm{m})$, and finally stained with hematoxylin and eosin and fixed on a slide. Collect the digital images using a Leica microscope (magnification was $100 \mathrm{x}$ ).

\subsection{Extraction of Nuclear and Cytoplasmic Protein Compo-} nents from Esophageal Tissues. The protein extraction process of the cells was carried out in accordance with the method described by Komatsu and colleagues [32]. Briefly, the esophageal tissue was weighed and homogenized in tissue lysis buffer contained with protease inhibitor cocktail, $10 \mathrm{mM}$ HEPES (pH 7.8), $10 \mathrm{mM} \mathrm{KCl,} 2 \mathrm{mM} \mathrm{MgCl}$, $0.1 \mathrm{mM}$ EDTA, $0.1 \mathrm{mM}$ PMSF, and $1 \mathrm{mM}$ DTT. Then the lysate was placed on ice for $30 \mathrm{~min}$ and mixed once every $10 \mathrm{~min}$. The lysate was centrifuged at $13,000 \mathrm{rpm}$ for $3 \mathrm{~min}$ at $4^{\circ} \mathrm{C}$, and the supernatant containing cytoplasmic protein component was collected. The bottom pellet was resuspended with lysis buffer with protease inhibitor cocktail, $50 \mathrm{mM}$ HEPES ( $\mathrm{pH} 7.8$ ), $50 \mathrm{mM} \mathrm{KCl}, 300 \mathrm{mM} \mathrm{NaCl}, 1 \mathrm{mM}$ DTT, $0.1 \mathrm{mM}$ EDTA, $0.1 \mathrm{mM}$ PMSF, and $1 \%$ glycerol. The lysate were placed on ice for $30 \mathrm{~min}$, mixed once every $10 \mathrm{~min}$, and centrifuged at $13,000 \mathrm{rpm}$ for $15 \mathrm{~min}$ at $4^{\circ} \mathrm{C}$. Finally, collect supernatant containing nuclear protein components and store at $-80^{\circ} \mathrm{C}$ until used.

2.10. Western Blot Analysis. The loading sample was separated by SDS-PAGE, transferred to a PVDF membrane and then blocked with 5\% skim milk for $1 \mathrm{~h} 30 \mathrm{~min}$ at room temperature. Membranes were incubated with primary antibodies $(1: 1,000)$ against iNOS, COX-2, TNF- $\alpha$, IL- $1 \beta$, p$\mathrm{NF}-\kappa \mathrm{B}$ p $65, \mathrm{p}-\mathrm{I} \kappa \mathrm{B} \alpha$, histone, and $\beta$-actin at $4^{\circ} \mathrm{C}$ overnight. Then, the secondary antibody was added to react at room temperature for $1.5 \mathrm{~h}$ with gentle agitation. Bands were visualized using western blotting Luminol Reagent solutions $\mathrm{A}$ and $\mathrm{B}$ at a 1:1 proportion. Images were acquired with BioRad imaging software (Fuji, New York, NY, USA).

2.11. Statistical Analysis. All data results are mean \pm standard deviation. Significant evaluation was performed by one-way analysis of variance and LDS's multiple comparison test, statistically significant at $\mathrm{p}<0.05$.

\section{Results}

3.1. AHE Treatment Does Not Affect Cell Viability. The effect of AHE on the viability of RAW264.7 cells was evaluated using the Cell Viability, Proliferation \& Cytotoxicity Assay Kit. No significant effects on cell viability were detected following $24 \mathrm{~h}$ incubation with $\mathrm{AHE}$ at concentrations of 125 , 250, and $500 \mu \mathrm{g} / \mathrm{ml}$ (Figure 1(a)).

3.2. AHE Treatment Inhibits the Production of LPS-Induced $N O$ and $i N O S$. As shown in Figure 1(b), the production of NO was inhibited by treatment with AHE in a concentrationdependent manner. The expression level of iNOS, a protein regulated by $\mathrm{NF}-\kappa \mathrm{B}$ activity, was also reduced in a dosedependent manner (Figure 1(c)).

3.3. AHE Treatment Inhibits LPS-Induced Production of COX2 and $I L-1 \beta$. To investigate the expression levels of COX-2 and IL- $1 \beta$, cells were incubated with varying concentrations of AHE for $1 \mathrm{~h}$ prior to stimulation with LPS $(1 \mu \mathrm{g} / \mathrm{ml})$ for 18 h. As shown in Figure 1(d), AHE inhibited COX-2 expression in a concentration-dependent manner. In addition, AHE suppressed the expression level of the proinflammatory cytokine IL-1 $\beta$ (Figure 1(e)).

3.4. AHE Treatment Inhibits LPS-Induced NF- $\kappa B$ Activation. To investigate whether AHE treatment regulates the NF$\kappa \mathrm{B}$ signaling pathway, cells were treated with different concentrations of AHE for $1 \mathrm{~h}$ and then stimulated with LPS $(1 \mu \mathrm{g} / \mathrm{ml})$ for another $1 \mathrm{~h}$. As shown in Figure 2(a), AHE significantly inhibited the expression of phosphorylated NF$\kappa \mathrm{B}$. The expression level of phosphorylated $\mathrm{I} \kappa \mathrm{B} \alpha$ was also inhibited after AHE treatment (Figure 2(b)).

3.5. AHE Treatment Attenuates Gross Mucosal Damage of the Esophagus in RE Rat. As shown on Figure 3(a)-i, in the normal group, no damage of rat esophagus was observed, but in the RE control group, the rat's esophagus showed severe damage, including congestion and multiple erosions. In the AHE treatment group, it can be seen that the esophageal injury is significantly reduced. As shown on Figure 3(b), gross mucosal damage ratio in AHE group was significantly lower than that in RE control group. In addition, it can be seen from histological staining that the normal mucosal epithelium was observed in the normal group and showed a thin epithelial layer, and there was no infiltration of inflammatory cells in the submucosa. Conversely, significant tissue damage can be observed in the RE control group, showing mucosal damage to the esophageal tissue, massive loss of epithelial cells, marked epithelial hyperemia, and mucosal and submucosal hemorrhage, while significantly less damage to the esophageal tissue was seen in mice that had received oral AHE (500 mg/kg) (Figure 3(a)-ii).

3.6. AHE Treatment Reduces the Expression of Proinflammatory Mediators in the RE Rat Esophagus. As shown in Figure 4, the expression levels of mediators related to inflammation and inflammatory cytokines, including COX-2 (a), 


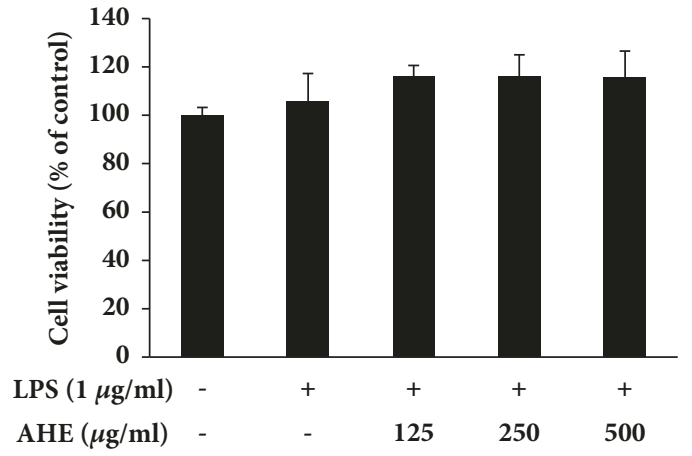

(a)

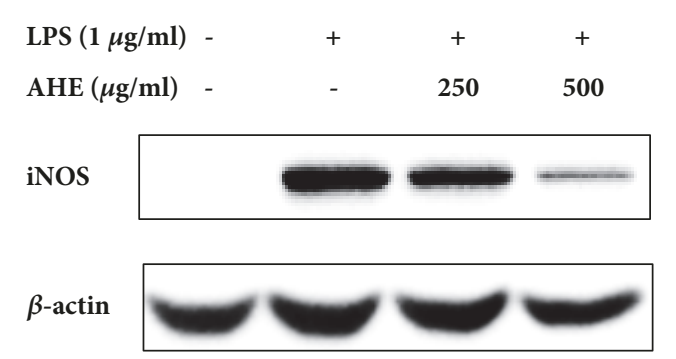

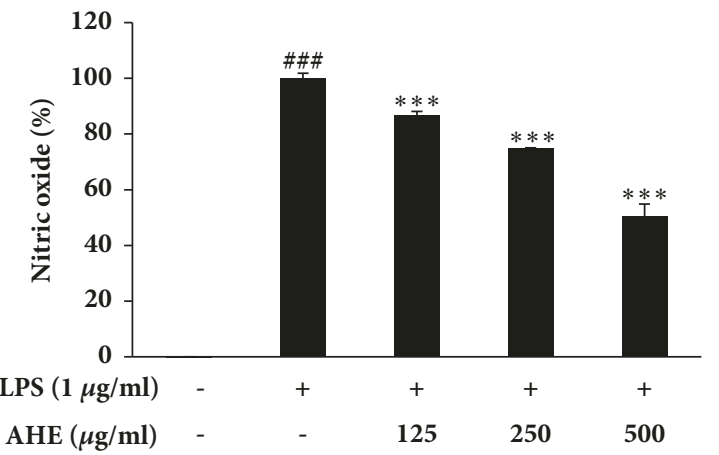

(b)

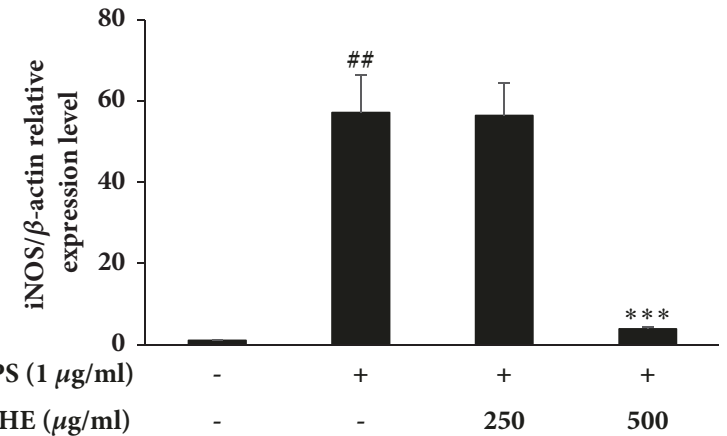

(c)

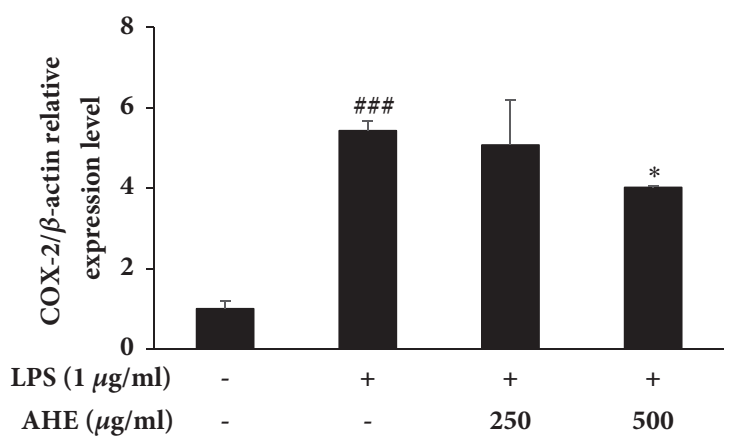

(d)
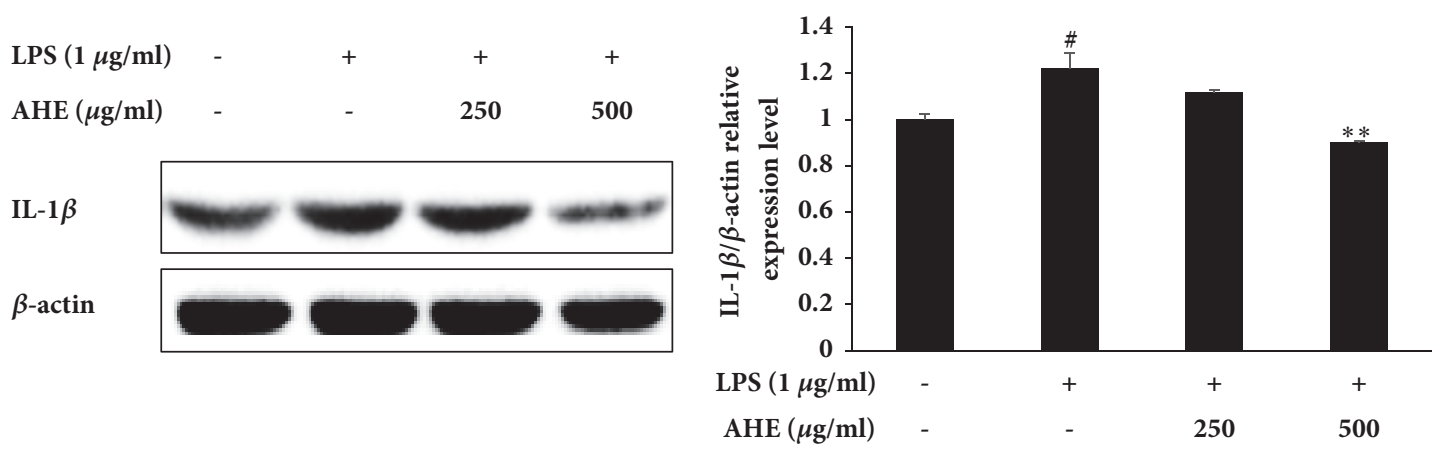

(e)

FIGURE 1: Safety and anti-inflammatory activities of AHE in LPS-induced RAW264.7 cells. The cells were treated with AHE at various concentrations for $1 \mathrm{~h}$ and then stimulated, or not, with LPS for $24 \mathrm{~h}$ or $18 \mathrm{~h}$. Cell viability (a) was assayed by the Cell Viability, Proliferation \& Cytotoxicity Assay Kit, and the production of NO (b) was measured using the Griess test. The expression levels of iNOS (c), COX-2 (d), and IL-1 $\beta$ (e) in LPS-induced RAW264.7 cells were measured using western blot assay. Values are presented as the mean \pm standard deviation of three independent experiments. ${ }^{\# \# *} \mathrm{P}<0.001,{ }^{\# \#} \mathrm{P}<0.01$, and ${ }^{\#} \mathrm{P}<0.05$ versus unstimulated cells; ${ }^{* * *} \mathrm{P}<0.001,{ }^{* *} \mathrm{P}<0.01$, and ${ }^{*} \mathrm{P}<0.05$ versus LPS-stimulated cells. 


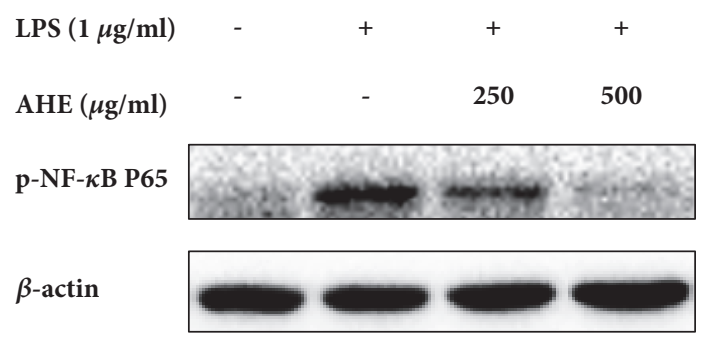

(a)

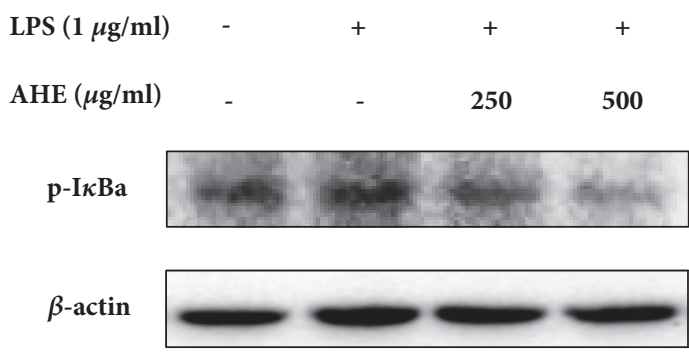

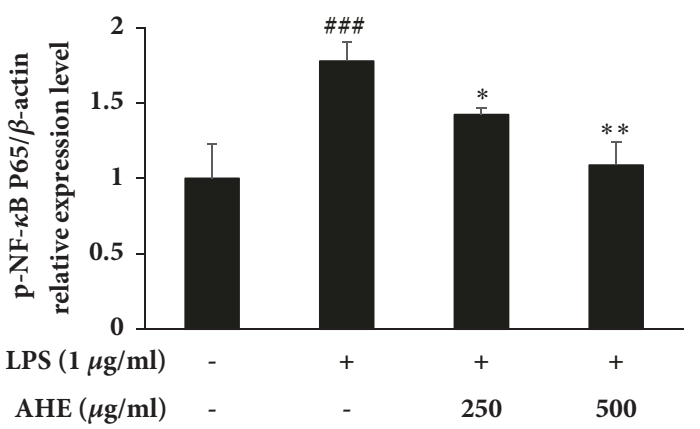

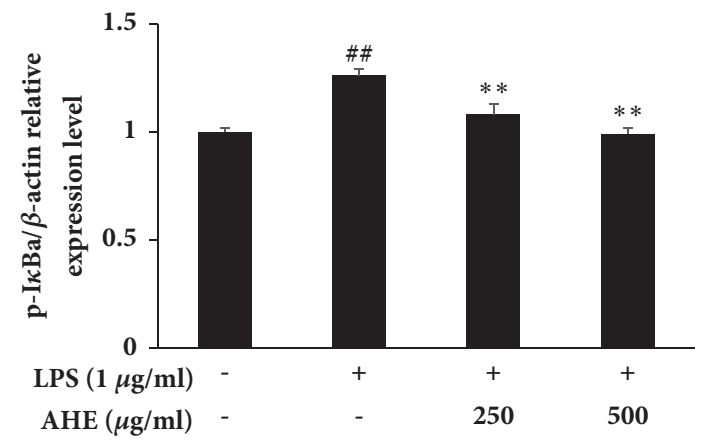

(b)

FIGURE 2: The signaling pathway involved in the anti-inflammatory activities of AHE in LPS-induced RAW264.7 cells. The expression levels of p-NF- $\kappa \mathrm{B}(\mathrm{a})$ and $\mathrm{p}-\mathrm{I} \kappa \mathrm{B} \alpha(\mathrm{b})$ in LPS-induced RAW264.7 cells were measured using western blot assay. Values are presented as the mean \pm standard deviation of three independent experiments. ${ }^{\# \# \#} \mathrm{P}<0.001,{ }^{\# \#} \mathrm{P}<0.01$, and ${ }^{\#} \mathrm{P}<0.05$ versus unstimulated cells; ${ }^{* *} \mathrm{P}<0.01$ and ${ }^{*} \mathrm{P}<0.05$ versus LPS-stimulated cells.
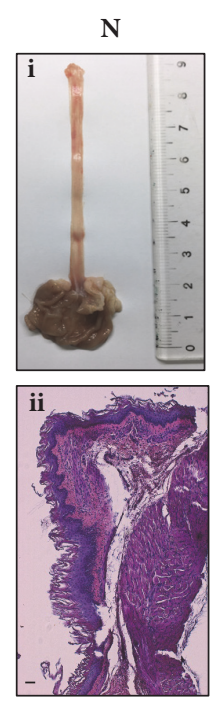

(a)

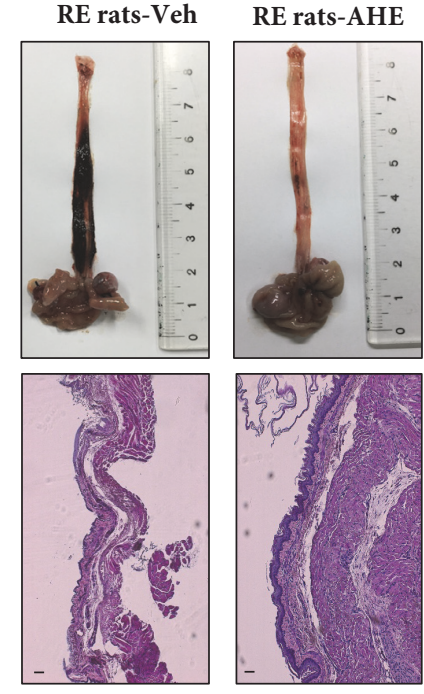

FIGURE 3: Effect of AHE on RE rats. Morphological ((a)-i) and histological ((a)-ii) examination of the esophagus in each group. Gross mucosal damage ratio (b). N, normal rats; Veh, RE control rats; AHE, RE control rats treated with $500 \mathrm{mg} / \mathrm{kg}$ AHE (scale bar $200 \mu \mathrm{m}$ ). Values are presented as the mean \pm standard deviation. ${ }^{*} \mathrm{P}<0.05$ versus $\mathrm{RE}$ control rats.

IL-1 $\beta$ (b), and TNF- $\alpha$ (c), were reduced in AHE-treated $\mathrm{RE}$ rats when compared with $\mathrm{RE}$ control rats. In addition, the expression levels of $\mathrm{p}-\mathrm{NF}-\kappa \mathrm{B}(\mathrm{d})$ and $\mathrm{p}-\mathrm{I} \kappa \mathrm{B} \alpha$ (e) were increased in the esophagus tissue of RE rats, while these levels were markedly decreased in the AHE-treated RE rats.

\section{Discussion}

In this study, we first observed the inhibitory effect of AHE on LPS-induced inflammation. We found that AHE treatment of LPS-induced RAW264.7 cells markedly inhibited the 


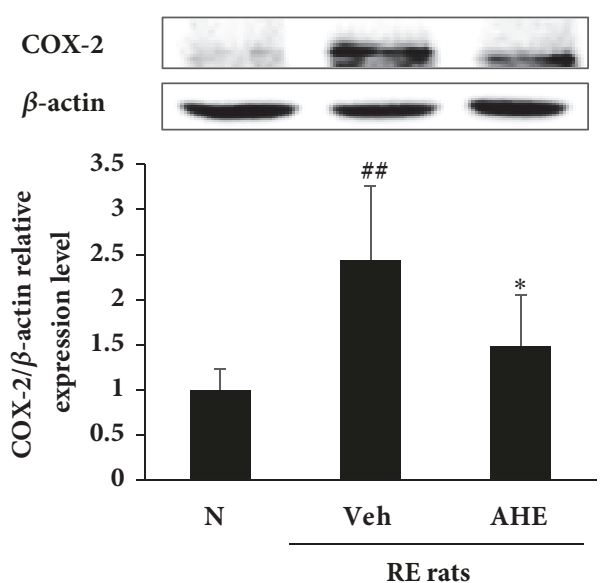

(a)

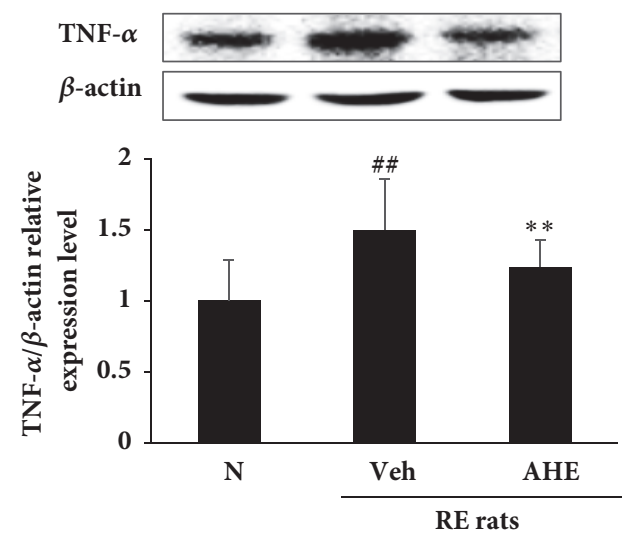

(c)

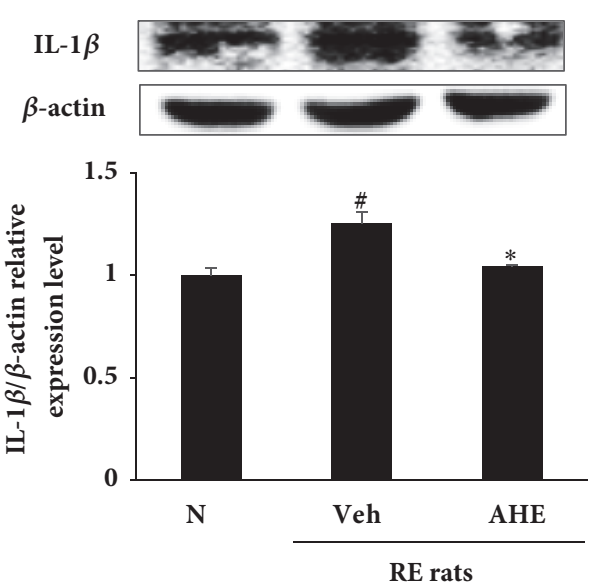

(b)

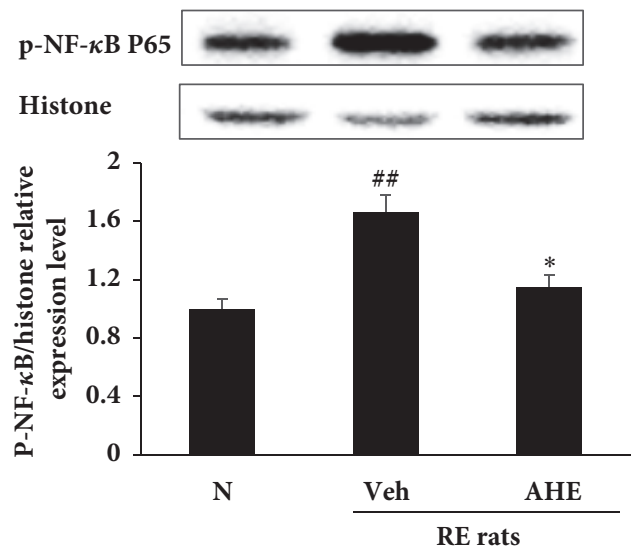

(d)

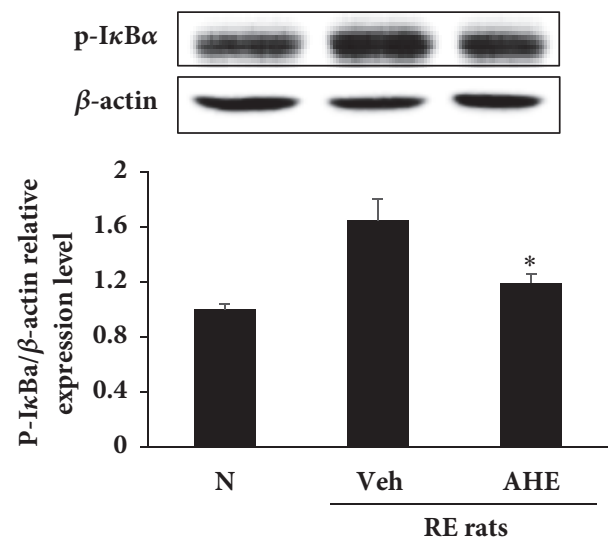

(e)

FIGURE 4: Effects of AHE on the expression levels of COX-2 (a), IL-1 $\beta$ (b), and TNF- $\alpha$ (c) and the phosphorylation levels of NF- $\kappa$ B (d) and $\mathrm{I} \kappa \mathrm{B} \alpha(\mathrm{e})$ in rat esophageal tissue were measured using western blot assay. $\mathrm{N}$, normal rats; Veh, RE control rats; AHE, RE control rats treated with $500 \mathrm{mg} / \mathrm{kg}$ AHE. ${ }^{\#} \mathrm{P}<0.01$ and ${ }^{\#} \mathrm{P}<0.05$ versus normal rats; ${ }^{* *} \mathrm{P}<0.01$ and ${ }^{*} \mathrm{P}<0.05$ versus $\mathrm{RE}$ control rats.

production of NO, mediators related to inflammation such as iNOS and COX-2, and cytokines such as IL- $1 \beta$ and TNF- $\alpha$. In addition, AHE decreased the phosphorylation of NF- $\kappa \mathrm{B}$ and $\mathrm{p}-\mathrm{I} \kappa \mathrm{B} \alpha$. We then investigated whether AHE has protective effects against the development of experimental rat RE. The administration of AHE was found to alleviate the degree of esophageal tissue mucosal damage and the protein expression levels of inflammatory mediators and cytokines associated with RE.

Inflammation is an innate immune response of the host to foreign aggressions such as pathogens, bacteria, and tissue damage [33]. The inflammatory response occurs in many 
types of cells, including macrophages and monocytes. When the inflammatory reaction occurs, the body mainly manifests as redness, fever, swelling, and dysfunction [34]. RE is a common gastroesophageal reflux disease that is common in Europe and other areas that seriously affects the quality of life of human beings. In recent years, there has also been a gradual upward trend in the Asian region $[35,36]$. Persistent esophageal reflux can lead to esophageal inflammation, and prolonged esophagitis is likely to induce esophageal cancer.

The NF- $\kappa \mathrm{B}$ transcription factor comprises five dimeric complexes such as p65 (RelA), c-Rel, RelB, p50, and p52. Each of these dimeric complexes has a 300-residue N-terminal Rel-homologous domain, which is primarily responsible for dimerization, nuclear transfer, and DNA binding. [37, 38]. The NF- $\kappa \mathrm{B}$ signaling pathway is thought to be a classical signal transduction pathway regulating inflammatory responses. NF- $\kappa \mathrm{B}$ is activated by stimulants such as LPS and separated from its inhibitory protein $\mathrm{I} \kappa \mathrm{B}$ and transferred into the nucleus to promote gene expression of inflammationrelated factors [39]. In resting cells, NF- $\kappa \mathrm{B}$ is mainly present in the cytoplasm, and $\mathrm{I} \kappa \mathrm{B}$ proteins inhibit their activity by masking their nuclear localization sequences (NLSs). Excessive activation of NF- $\kappa \mathrm{B}$ may lead to the development of a variety of inflammatory diseases and even cancer [40]. Activated NF- $\kappa \mathrm{B}$ enters the nucleus to bind to DNA and induce the transcription of target genes such as TNF- $\alpha$ and IL- $1 \beta$. It also regulates the expression of inducible enzymes such as iNOS and COX-2.

In this study, AHE treatment showed promising effects against LPS-induced inflammation in RAW264.7 cells. Furthermore, AHE treatment of the RE rats obviously inhibited upregulation of inflammatory mediators related to $\mathrm{NF}-\kappa \mathrm{B}$ signaling in esophageal tissue. In addition, the expression levels of TNF- $\alpha$ and IL- $1 \beta$ in the RE model were significantly downregulated by the administration of AHE.

\section{Conclusions}

In conclusion, we demonstrated that AHE inhibits LPSinduced inflammation of macrophage RAW 264.7 cells by inhibiting NF- $\kappa \mathrm{B}$ activation. At the same time, we also found that treatment with AHE can effectively improve the damage of the esophageal mucosa in the rat model of RE and inhibit the expression of inflammatory mediators and cytokines regulated by $\mathrm{NF}-\kappa \mathrm{B}$. In summary, our data extend the existing potential of medicinal use of $A$. hookeri.

\author{
Abbreviations \\ AHE: Allium hookeri root extract \\ GERD: Gastroesophageal reflux disease \\ RE: Reflux esophagitis \\ LPS: Lipopolysaccharide \\ NO: $\quad$ Nitric oxide \\ iNOS: Inducible nitric oxide synthase \\ COX-2: Cyclooxygenase- 2 \\ IL-1 $\beta$ : Interleukin- $1 \beta$ \\ TNF- $\alpha$ : Tumor necrosis factor- $\alpha$ \\ NF- $\kappa$ B: Nuclear factor $\kappa \mathrm{B}$
}

$\mathrm{I} \kappa \mathrm{B} \alpha$ : Nuclear factor of kappa light polypeptide gene enhancer in B-cells inhibitor- $\alpha$

EDTA: Ethylenediaminetetraacetic acid

H\&E: Hematoxylin and eosin

HEPES: 4-(2-Hydroxyethyl)-1piperazineethanesulfonic acid

SDS: Sodium dodecyl sulfate

DTT: DL-Dithiothreitol

PMSF: Phenylmethylsulfonyl fluoride

EDTA: Ethylenediaminetetraacetic acid

PVDF: Polyvinylidene fluoride membranes

ATCC: American Type Culture Collection.

\section{Data Availability}

The data used to support the findings of this study are available from the corresponding author upon request.

\section{Conflicts of Interest}

The authors declare that there are no conflicts of interest regarding the publication of this paper.

\section{Authors' Contributions}

Li Nan and Hyeon Hwa Nam contributed equally to this work.

\section{Acknowledgments}

This work was carried out with the support of the Sunchang Research Institute of Health and Longevity [Grant no. 1601002054].

\section{References}

[1] F. Rieder, P. Biancani, K. Harnett, L. Yerian, and G. W. Falk, "Inflammatory mediators in gastroesophageal reflux disease: impact on esophageal motility, fibrosis, and carcinogenesis," American Journal of Physiology-Gastrointestinal and Liver Physiology, vol. 298, no. 5, pp. G571-G581, 2010.

[2] O. T. Nebel, M. F. Fornes, and D. O. Castell, "Symptomatic gastroesophageal reflux: Incidence and precipitating factors," American Journal of Digestive Diseases, vol. 21, no. 11, pp. 953956, 1976.

[3] H. B. El-Serag, "Time trends of gastroesophageal reflux disease: a systematic review," Clinical Gastroenterology and Hepatology, vol. 5, no. 1, pp. 17-26, 2007.

[4] R. Badillo and D. Francis, "Diagnosis and treatment of gastroesophageal reflux disease," World Journal of Gastrointestinal Pharmacology and Therapeutics, vol. 5, no. 3, pp. 105-112, 2014.

[5] H. B. El-Serag, S. Sweet, C. C. Winchester, and J. Dent, "Update on the epidemiology of gastro-oesophageal reflux disease: A systematic review," Gut, vol. 63, no. 6, pp. 871-880, 2014.

[6] T. J. Wieczorek, H. H. Wang, D. A. Antonioli, J. N. Glickman, and R. D. Odze, "Pathologic features of reflux and Helicobacter pylori-associated carditis: A comparative study," The American Journal of Surgical Pathology, vol. 27, no. 7, pp. 960-968, 2003. 
[7] T.-Y. Oh, J.-S. Lee, B.-O. Ahn et al., "Oxidative damages are critical in pathogenesis of reflux esophagitis: implication of antioxidants in its treatment," Free Radical Biology \& Medicine, vol. 30, no. 8, pp. 905-915, 2001.

[8] X. Gong, Y. Yang, L. Huang et al., "Antioxidation, antiinflammation and anti-apoptosis by paeonol in LPS/D-GalNinduced acute liver failure in mice," International Immunopharmacology, vol. 46, pp. 124-132, 2017.

[9] J.-H. Yang, Y.-H. Hwang, M.-J. Gu, W.-K. Cho, and J. Y. Ma, "Ethanol extracts of Sanguisorba officinalis L. suppress TNF$\alpha /$ IFN- $\gamma$-induced pro-inflammatory chemokine production in HaCaT cells," Phytomedicine, vol. 22, no. 14, pp. 1262-1268, 2015.

[10] E. B. Thorgersen, A. Macagno, C. Rossetti, and T. E. Mollnes, "Cyanobacterial LPS antagonist (CyP)-A novel and efficient inhibitor of Escherichia coli LPS-induced cytokine response in the pig," Molecular Immunology, vol. 45, no. 13, pp. 3553-3557, 2008.

[11] M. Gasparrini, T. Y. Forbes-Hernandez, F. Giampieri et al., "Anti-inflammatory effect of strawberry extract against LPSinduced stress in RAW 264.7 macrophages," Food and Chemical Toxicology, vol. 102, pp. 1-10, 2017.

[12] J.-Y. Jang, M.-J. Lee, B.-R. You et al., "Allium hookeri root extract exerts anti-inflammatory effects by nuclear factor$\kappa \mathrm{B}$ down-regulation in lipopolysaccharide-induced RAW264.7 cells," BMC Complementary and Alternative Medicine, vol. 17, no. 1, 2017.

[13] J. Liu, J. Tang, Y. Zuo et al., "Stauntoside B inhibits macrophage activation by inhibiting NF- $\kappa \mathrm{B}$ and ERK MAPK signalling," Pharmacological Research, vol. 111, pp. 303-315, 2016.

[14] W. Vanden Berghe, S. Plaisance, E. Boone et al., "p38 and extracellular signal-regulated kinase mitogen-activated protein kinase pathways are required for nuclear factor- $\kappa \mathrm{B}$ p 65 transactivation mediated by tumor necrosis factor," The Journal of Biological Chemistry, vol. 273, no. 6, pp. 3285-3290, 1998.

[15] D. H. Williams, L. J. Jeffery, and E. J. Murray, "Aurothioglucose inhibits induced NF- $\kappa$ B and AP-1 activity by acting as an IL1 functional antagonist," Biochimica et Biophysica Acta (BBA) Molecular Basis of Disease, vol. 1180, no. 1, pp. 9-14, 1992.

[16] J.-H. Hwang, K.-J. Kim, S.-J. Ryu, and B.-Y. Lee, "Caffeine prevents LPS-induced inflammatory responses in RAW264.7 cells and zebrafish," Chemico-Biological Interactions, vol. 248, pp. 1-7, 2016.

[17] G. Sharma, R. N. Gohil, and V. Kaul, "Cytological status of Allium hookeri Thwaites $(2 \mathrm{n}=22)$," Genetic Resources and Crop Evolution, vol. 58, no. 7, pp. 1041-1050, 2011.

[18] V. Ayam, “Allium hookeri, Thw. Enum. A lesser known terrestrial perennial herb used as food and its ethnobotanical relevance in Manipur," African Journal of Food, Agriculture, Nutrition and Development, vol. 11, no. 6, pp. 5389-5412, 2011.

[19] J.-Y. Park and K.-Y. Yoon, "Comparison of the nutrient composition and quality of the root of Allium hookeri grown in Korea and Myanmar," Korean Journal of Food Science and Technology, vol. 46, no. 5, pp. 544-548, 2014.

[20] G. C. Bae and D. Y. Bae, "The anti-inflammatory effects of ethanol extract of Allium Hookeri cultivated in South Korea," The Korea Journal of Herbology, vol. 27, no. 6, pp. 55-61, 2012.

[21] Y. Lee, S.-H. Lee, U. D. Gadde, S.-T. Oh, S.-J. Lee, and H. S. Lillehoj, "Dietary Allium hookeri reduces inflammatory response and increases expression of intestinal tight junction proteins in LPS-induced young broiler chicken," Research in Veterinary Science, vol. 112, pp. 149-155, 2017.
[22] Y.-L. Wang, X.-Y. Guo, W. He, R.-J. Chen, and R. Zhuang, "Effects of alliin on LPS-induced acute lung injury by activating PPAR $\gamma$," Microbial Pathogenesis, vol. 110, pp. 375-379, 2017.

[23] S. Roh, O. J. Kwon, J. H. Yang et al., "Allium hookeri root protects oxidative stress-induced inflammatory responses and $\beta$-cell damage in pancreas of streptozotocin-induced diabetic rats," BMC Complementary and Alternative Medicine, vol. 16, no. $1,2016$.

[24] M. Keusgen, "Health and alliums," in Allium Crop ScienceRecent Advances, pp. 357-378, CABI, Wallingford, UK, 2002.

[25] K. D. Singh, D. Chetia, and S. Mazumdar, "Anti-diabetic activity of methanolic extract of Allium hookeri leaves," Indo American Journal of Pharmaceutical Research, vol. 3, no. 5, pp. 4089-4104, 2013.

[26] H. S. Yang, Y. J. Choi, H. Y. Jin, S. C. Lee, and C. K. Huh, "Effects of Allium hookeri root water extracts on inhibition of adipogenesis and GLUT-4 expression in 3T3-L1 adipocytes," Food Science and Biotechnology, vol. 25, no. 2, pp. 615-621, 2016.

[27] R. Li, Y.-F. Wang, Q. Sun, and H.-B. Hu, "Chemical composition and antimicrobial activity of the essential oil from Allium hookeri consumed in Xishuangbanna, Southwest China," Natural Product Communications (NPC), vol. 9, no. 6, pp. 863-864, 2014.

[28] N. S. Kim, "Effects of Allium hookeri on glucose metabolism in type II diabetic mice," Korean Journal of Pharmacognosy, vol. 46, no. 1, pp. 78-83, 2015.

[29] H. Park, J. Jeong, H. Hyun et al., "Effects of a Hot-Water Extract of Allium hookeri Roots on Bone Formation in Human Osteoblast-Like MG-63 Cells In Vitro and in Rats In Vivo," Planta Medica, vol. 82, no. 16, pp. 1410-1415, 2016.

[30] E. V. Gaia Filho, A. Goldenberg, and H. O. Costa, "Experimental model of gastroesophageal reflux in rats," Acta Cirurgica Brasileira, vol. 20, no. 6, pp. 437-444, 2005.

[31] J. Schindelin, I. Arganda-Carreras, and E. Frise, "Fiji: an opensource platform for biological-image analysis," Nature Methods, vol. 28, no. 7, pp. 676-682, 2012.

[32] S. Komatsu, "Extraction of nuclear proteins," Methods in Molecular Biology, vol. 355, pp. 355-373, 2007.

[33] R. Medzhitov, "Origin and physiological roles of inflammation," Nature, vol. 454, no. 7203, pp. 428-435, 2008.

[34] S. E. Headland and L. V. Norling, "The resolution of inflammation: principles and challenges," Seminars in Immunology, vol. 27, no. 3, pp. 149-160, 2015.

[35] J. Dent, H. B. El-Serag, M.-A. Wallander, and S. Johansson, "Epidemiology of gastro-oesophageal reflux disease: a systematic review," Gut, vol. 54, no. 5, pp. 10-17, 2005.

[36] R. H. Riddell, "The biopsy diagnosis of gastroesophageal reflux disease, 'Carditis', and Barrett's esophagus, and sequelae of therapy," The American Journal of Surgical Pathology, vol. 20, no. 1, pp. 31-50, 1996.

[37] F. Wan, D. E. Anderson, R. A. Barnitz et al., "Ribosomal protein S3: a $\mathrm{KH}$ domain subunit in NF- $\kappa \mathrm{B}$ complexes that mediates selective gene regulation," Cell, vol. 131, no. 5, pp. 927-939, 2007.

[38] M. S. Hayden and S. Ghosh, "Shared principles in NF- $\kappa$ B signaling," Cell, vol. 132, no. 3, pp. 344-362, 2008.

[39] T. Lawrence, "The nuclear factor NF- $\kappa$ B pathway in inflammation," Cold Spring Harbor Perspectives in Biology, vol. 1, no. 6, 2009.

[40] P. N. Moynagh, “The NF- $\kappa$ B pathway,” Cell Science at a Glance, vol. 118, pp. 4389-4392, 2005. 


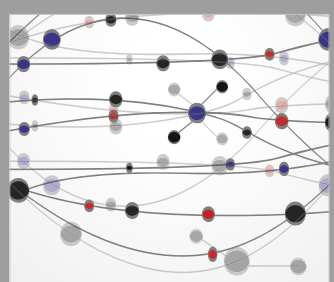

The Scientific World Journal
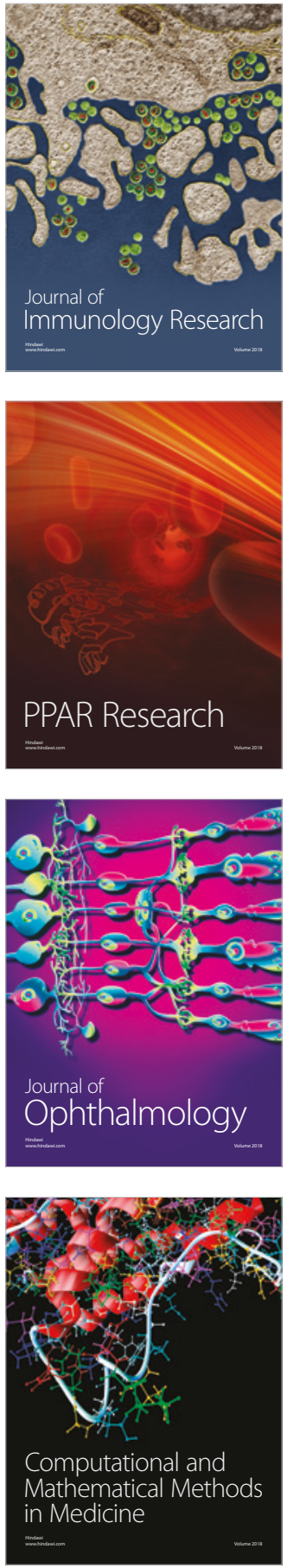

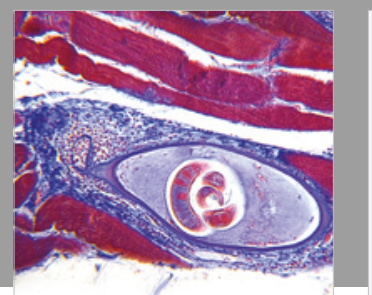

Gastroenterology Research and Practice

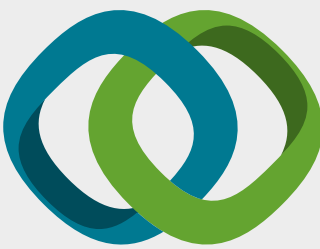

\section{Hindawi}

Submit your manuscripts at

www.hindawi.com
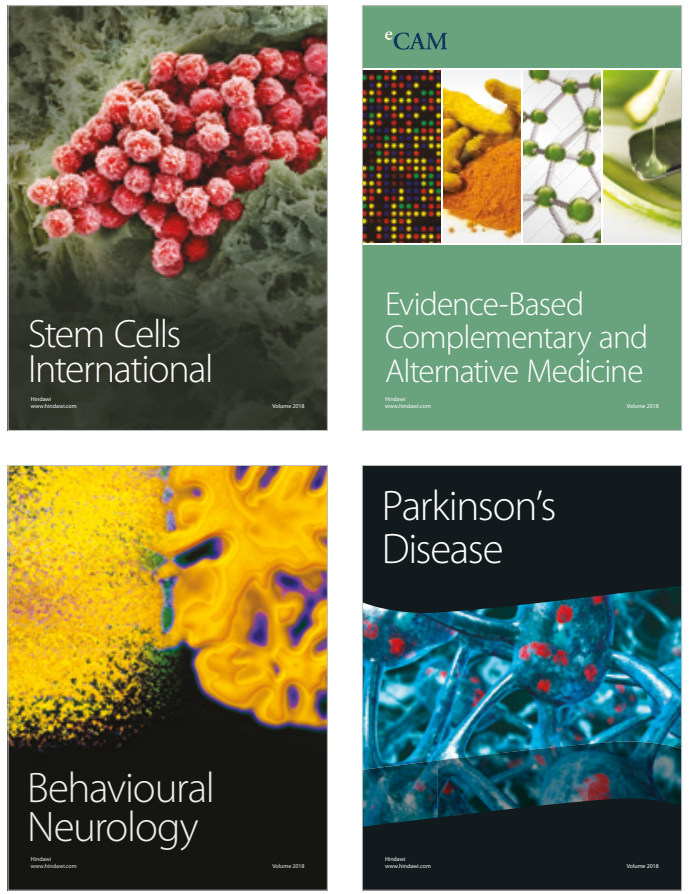

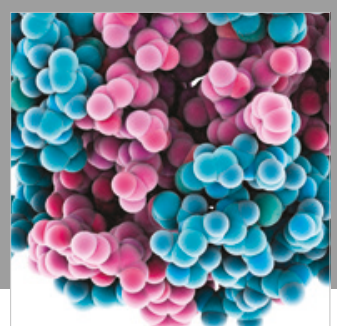

ournal of

Diabetes Research

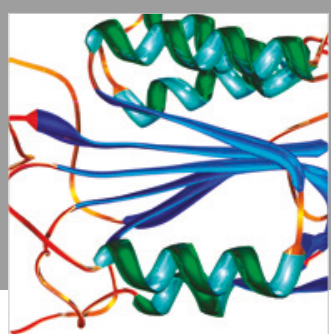

Disease Markers
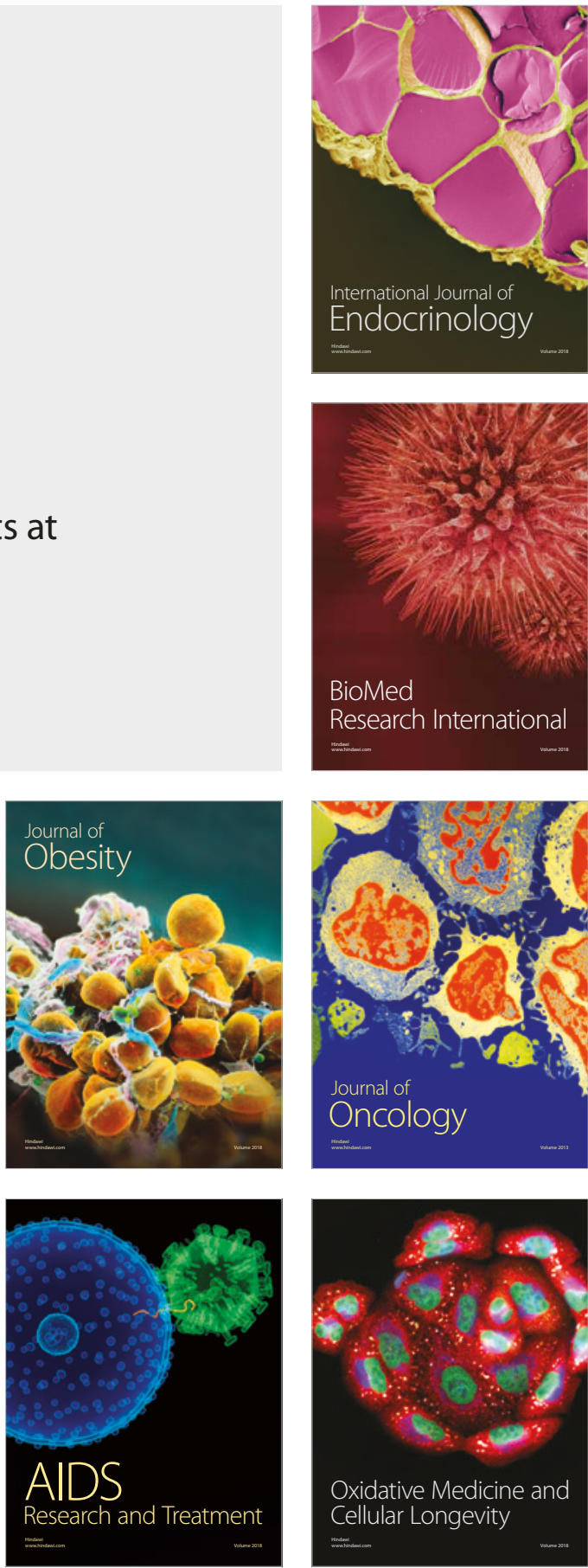